\title{
It's Good But it's Not Right: Instructional Self-Talk and Skilled Performance
}

Hardy, J.T.; Hardy, J.; Begley, K.; Blanchfield, A.W.

\section{Journal of Applied Sport Psychology}

DOI:

$10.1080 / 10413200.2014 .959624$

Published: 04/09/2014

Peer reviewed version

Cyswllt i'r cyhoeddiad / Link to publication

Dyfyniad o'r fersiwn a gyhoeddwyd / Citation for published version (APA):

Hardy, J. T., Hardy, J., Begley, K., \& Blanchfield, A. W. (2014). It's Good But it's Not Right: Instructional Self-Talk and Skilled Performance. Journal of Applied Sport Psychology. https://doi.org/10.1080/10413200.2014.959624

\section{Hawliau Cyffredinol / General rights}

Copyright and moral rights for the publications made accessible in the public portal are retained by the authors and/or other copyright owners and it is a condition of accessing publications that users recognise and abide by the legal requirements associated with these rights. study or research.

download and print one copy of any publication from the public portal for the purpose of private

- You may not further distribute the material or use it for any profit-making activity or commercial gain

- You may freely distribute the URL identifying the publication in the public portal ?

Take down policy

This is an Accepted Manuscript of an article published by Taylor \& Francis in Journal of Applied Sport Psychology on 04/09/2014, available online: http://dx.doi.org/10.1080/10413200.2014.959624

Take down policy

If you believe that this document breaches copyright please contact us providing details, and we will remove access to the work immediately and investigate your claim. 
This article was downloaded by: [Bangor University]

On: 06 November 2014, At: 00:57

Publisher: Routledge

Informa Ltd Registered in England and Wales Registered Number: 1072954 Registered office: Mortimer House, 37-41 Mortimer Street, London W1T 3J H, UK

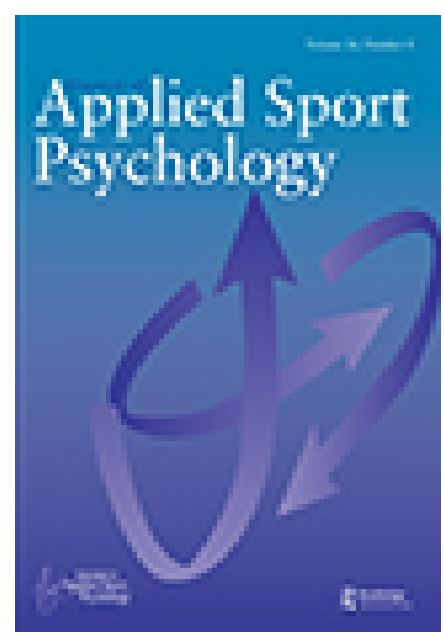

\title{
J ournal of Applied Sport Psychology
}

Publication details, including instructions for authors and subscription information:

http:// www. tandfonline.com/loi/ uasp20

\section{It's Good But it's Not Right: Instructional Self-Talk and Skilled Performance}

\author{
$J_{\text {James Hardy }}{ }^{\mathrm{a}}$, Keith Begley ${ }^{\mathrm{a}} \&$ Anthony W. Blanchfield ${ }^{\mathrm{a}}$ \\ ${ }^{a}$ Bangor University \\ Accepted author version posted online: 04 Sep 2014.
}

To cite this article: J ames Hardy, Keith Begley \& Anthony W. Blanchfield (2014): It's Good But it's Not Right: Instructional SelfTalk and Skilled Performance, J ournal of Applied Sport Psychology, DOI: 10.1080/ 10413200.2014.959624

To link to this article: http:// dx.doi.org/ 10.1080/ 10413200.2014.959624

Disclaimer: This is a version of an unedited manuscript that has been accepted for publication. As a service to authors and researchers we are providing this version of the accepted manuscript (AM). Copyediting, typesetting, and review of the resulting proof will be undertaken on this manuscript before final publication of the Version of Record (VoR). During production and pre-press, errors may be discovered which could affect the content, and all legal disclaimers that apply to the journal relate to this version also.

\section{PLEASE SCROLL DOWN FOR ARTICLE}

Taylor \& Francis makes every effort to ensure the accuracy of all the information (the "Content") contained in the publications on our platform. However, Taylor \& Francis, our agents, and our licensors make no representations or warranties whatsoever as to the accuracy, completeness, or suitability for any purpose of the Content. Any opinions and views expressed in this publication are the opinions and views of the authors, and are not the views of or endorsed by Taylor \& Francis. The accuracy of the Content should not be relied upon and should be independently verified with primary sources of information. Taylor and Francis shall not be liable for any losses, actions, claims, proceedings, demands, costs, expenses, damages, and other liabilities whatsoever or howsoever caused arising directly or indirectly in connection with, in relation to or arising out of the use of the Content.

This article may be used for research, teaching, and private study purposes. Any substantial or systematic reproduction, redistribution, reselling, loan, sub-licensing, systematic supply, or distribution in any form to anyone is expressly forbidden. Terms \& Conditions of access and use can be found at http:// www.tandfonline.com/page/terms-and-conditions 


\title{
ACCEPTED MANUSCRIPT
}

Running head: SELF-TALK \& SKILLED PERFORMANCE

It's Good But it's Not Right: Instructional Self-Talk and Skilled Performance

\author{
James Hardy, Keith Begley, and Anthony W. Blanchfield \\ Bangor University
}

Correspondence should be sent to James Hardy, Bangor University, School of Sport Health \& Exercise Sciences, Normal Site, Bangor University, Bangor, LL57 2PZ United Kingdom. Email: j.t.hardy@bangor.ac.uk

\begin{abstract}
This research examined the relative effectiveness of instructional versus motivational self-talk for skilled athletes. Forty Gaelic footballers completed a shooting accuracy task with their dominant and non-dominant feet. Results indicated significantly more accurate performance when executing the task using the dominant foot and motivational as compared to instructional self-talk. No difference emerged between the two types of self-talk within the non-dominant foot condition. Results challenge the widely held view that instructional self-talk is most effective for accuracy based tasks and should prompt practitioners to consider the skill level of their clients when constructing self-talk interventions.
\end{abstract}

Keywords: performance, self-focus, verbal cues, dominant / non-dominant limbs 


\section{ACCEPTED MANUSCRIPT}

It's good but it's not right: Instructional self-talk and skilled performance

Self-talk refers to statements that athletes say to themselves automatically or deliberately and as such can be said silently or out loud so that some one close by could here what is said; nevertheless the intended target of the phrase is the athlete themselves not the observer (cf. Hardy, Oliver, \& Tod, 2009). While a number of different types of self-talk have been identified in the self-talk literature (see Hardy, 2006 for a review), the present study examines skilled athletes' use of instructional and motivational self-talk. Instructional self-talk (e.g., "firm wrist") is typically technique or tactics oriented aiding concentration whereas motivational self-talk (e.g., "I can do this") is related to enhanced confidence, increased effort, and positive affective states. Research indicates that instructional self-talk can enhance the performance of motor skills. In fact, two relatively recent systematic reviews support the consistency of these performance benefits of instructional self-talk (Tod, Hardy, \& Oliver, 2011) and indicate a moderately strong positive effect on motor skill execution (Hatzigeorgiadis, Zourbanos, Galanis, \& Theordorakis, 2011). In order to provide practitioners with direction and guidance, Theodorakis, Weinberg, Natsis, Douma, and Kazakas (2000) put forward a matching hypothesis. Within this hypothesis instructional self-talk is proposed to be more effective than motivational self-talk for precision and outcome-based motor skills whereas the opposite is true for motor skills requiring strength and endurance. Instructional self-talk is proposed to be more helpful than motivational self-talk for accuracy oriented motor skills because instructional self-talk can facilitate performers' understanding of task requirements helping them to attend to task relevant cues aiding their concentration during task execution. 


\section{ACCEPTED MANUSCRIPT}

While there is little direct empirical support for this attention related mechanism within the self-talk literature, examination of the attentional focus literature suggests that attending to one's actions is not necessarily beneficial for performance (e.g., Wulf, 2007). This is particularly true for skilled performers (e.g., Beilock, Carr, MacMahon, \& Starkes, 2002; Bell \& Hardy, 2009), a level of athlete surprisingly under-represented in the self-talk literature. Within the attentional focus literature, some researchers have employed a dual-task paradigm in order to assess the effectiveness of self focus versus non-self focus of attention on task execution. As such participants carry out a primary task (e.g., dribbling a soccer ball around cones) while concurrently completing a secondary task (e.g., counting the number of bleeps presented during task execution) in order to manipulate self focus. Task execution related benefits for skilled performers of a non-self focus are evident within this literature (e.g., Beilock et al., 2002).

Beilock and colleagues' (2002) theorizing that attending to a task can disrupt well-groomed, automated motor execution, helps bolster and augment Zourbanos, Hatzigeorgiadis, Bardas, and Theodorakis (2013) study and subsequent findings. Zourbanos et al. assessed the benefits of instructional and motivational self-talk within a PE student (10-12 years old) population. The authors employed an elementary outcome based motor skill - the overhand throw. They argued that this was a well-learned skill for the PE students as it was a fundamental aspect of handball, a very popular sport commonly taught within PE lessons in Greece where the study took place. The study involved three groups (instructional self-talk, motivational self-talk and a control group) and a learning paradigm in which participants completed 18 learning trials after an initial baseline, in a counterbalanced order with their dominant/non-dominant hand. Zourbanos et al. found no inter-group differences between the two self-talk groups' dominant hand throwing 


\section{ACCEPTED MANUSCRIPT}

accuracy. Moreover very little evidence supporting a learning effect was present perhaps suggesting that a ceiling effect was in operation.

However, one of the strengths of the Zourbanous et al. (2013) study was that it also examined the effects of self-talk for non-dominant limb/hand performance. For instance, to be an asset within many team sports, such as soccer, rugby, Gaelic football, and fielding in cricket, athletes need to be competent using both dominant and non-dominant limbs. Despite the value coaches place in developing athletes' weaker aspects of their game, such as a right footed soccer player crossing the ball with her left foot, there remains a dearth of research on this issue. In particular, for the mental skill of self-talk there remains very little research able to indicate whether or not the effects of (instructional) self-talk hold for the performance of motor skills executed with the non-dominant limb. Whilst initial data presented by Zourbanos et al. (2013) appears to offer some support for an advantage of instructional over motivational self-talk for non-dominant hand throwing accuracy, there is reason to believe that this may not always be the case. For example, it is possible that the actual performance level demonstrated by skilled performers using their non-dominant limb may more closely resemble that of their unskilled counterparts. Nevertheless from a cognitive perspective the skilled performer is different and more advanced than a novice. In effect, the athlete executing a skill with his/her non-dominant limb will likely have a relatively under-developed image of achievement but have a welldeveloped image of the act (cf. Whiting \& den Brinker, 1981). In other words, although the performer may not have a well-developed understanding of the specifics concerning effective execution (e.g., the integration of proprioceptive information present during the task), he/she does have a reasonably good understanding of the general task requirements or mental 


\section{ACCEPTED MANUSCRIPT}

representation of the task. As a result, it is possible that the expected benefits of instructional self-talk for task execution may not be as pronounced as expected in Theordorakis et al.'s (2000) matching hypotheses; thus, this issue requires further investigation.

In addition to the aforementioned reasoning, further consideration of the age of their sample and the fact that cognitive neuroscience research indicates differences between how adults and children process verbal information (e.g., Schlaggar et al., 2002), it is likely that the generalizability of Zourbanos et al.'s (2013) findings remain somewhat limited. In the present study, we build off Zourbanos et al.'s study to examine the effectiveness of using instructional self-talk versus motivational self-talk for skilled adult athletes utilizing a complex, real-life outcome based motor skill; accuracy of free kick goal kicking in Gaelic football. Given that the main thrust of the present research was on skilled performers a learning paradigm was deemed inappropriate as participants would already be proficient at the experimental test. Furthermore, and as stated previously, data from dual-task paradigm studies illustrate the performance benefit for skilled athletes of employing a non-self focus of attention during task execution. That said, although useful for manipulating participants' focus of attention within the experimental context, unfortunately dual-task paradigm approaches lack ecological validity in practice and competitive sporting contexts. As a result, we propose that motivational self-talk may be a more user-friendly and applicable strategy for encouraging performers to adopt a non-self focus which should, in turn, benefit skilled performers' task execution.

In summary, the present study aims to generate an evidence base for practitioners by examining the relative effectiveness of instructional and motivational self-talk on familiar accuracy based kicking performance employing skilled athletes using their dominant and non- 


\section{ACCEPTED MANUSCRIPT}

dominant feet. We hypothesized that instructional self-talk will be more beneficial than motivational self-talk for the non-dominant foot condition; whereas motivational self-talk should be more beneficial than instructional self-talk for skilled dominant foot task execution.

\section{Method}

\section{Participants and study design}

Forty-one male Gaelic football players $\left(M_{\text {age }}=20.96\right.$ years; $S D=5.3$ years $)$ participated voluntarily in this study. All participants were experienced in Gaelic football $(M=11.78$ years; $S D=4.71)$, trained regularly $(M=5.38$ hours per week; $S D=2.14)$, and competed at the intercounty (under 18, under 21 or Senior) level. As each participant was his team's designated free kick taker, all participants were highly skilled in the experimental task. The study employed a $2 \mathrm{x}$ 2 (self-talk $\mathrm{x}$ foot) fully repeated measures randomized counter balanced design. All participants were tested in both self-talk instructional and motivational conditions using both (their dominant and non-dominant) feet.

\section{Experimental task and apparatus}

Participants completed 12 GAA free kicks at goal (three consecutive kicks from a single location; four locations in all at 39.52 and 50.60 degree angles from either side of the goal posts) within each of the four experimental conditions. As inter-county free takers have the capability to score comfortably from a distance of $35 \mathrm{~m}$, all kicks were taken from $22 \mathrm{~m}$, to ensure that task execution relied on accuracy not strength. Two points were awarded each time the ball went over the bar and between the posts, one point was awarded for a near miss (i.e., ball striking the post or crossbar), and no points were allocated for a complete miss of the target. Thus the maximum score for each condition was 24 points. Testing involved the use of Gaelic Athletic Association 


\section{ACCEPTED MANUSCRIPT}

approved equipment; goalposts (6.5 m wide; crossbar $2.5 \mathrm{~m}$ above the ground) and footballs (O’Neill size 5).

\section{Procedures}

Institutional ethical approval was first obtained. Prior to testing, participants completed informed consent forms and a demographic questionnaire. Participants abstained from participation in physical activity in the 24 hours preceding testing to eliminate the possibility of fatigue impacting on performance. Participants also abstained from alcohol consumption 24 hours prior to participation as alcohol has been shown to impair perceptual skills and motor dexterity (Hanchar, Dodson, Olsen, Otis, \& Wallner, 2005). A standardised 10min warm-up was completed by participants prior to data collection. Participants then executed two practice kicks off their dominant leg, from a $22 \mathrm{~m}$ distance directly in front of the goal, to familiarise themselves with the task. Participants were not permitted to do any shooting practice prior to this or between trials.

The self-talk statements used were based on Landin's (1994) recommendations; that is, brief and phonetically simple; logical and associated with the specific element of the skill; conformed to the sequence and timing of the skill for the instructional self-talk statement with both statements similar in length (and cognitive load). Both self-talk phrases were verified by two Level 2 GAA coaching tutors. The instructional self-talk statement used was "Target, stitches, one, two, laces and through". This phrase represented a preparation and initiation phase. "Target, stitches" formed part of the preparation whereby the word "Target" represented getting the shoulder line on the target while "stitches" represents participants looking at the

object they want to influence with their movement; that is, the football. The initiation element 


\section{ACCEPTED MANUSCRIPT}

"One, two, laces and through" represents the steps before the kick, striking the ball with the top of the foot (i.e., shoe laces) delivering the ball over the crossbar and between the posts. The motivational self-talk statement used was "Come on, I can get this". Both statements were explained to the participants before their first kick in the given condition. Participants were instructed to say the relevant self-talk statement aloud before each kick.

After completion of each of the conditions and prior to participation in the following condition, participants completed a self-report manipulation check form. After which participants counted backwards and aloud from a figure between 150 and 159 (chosen by the experimenter) to 0 in sevens with the intention being to reduce the likelihood of carry over effects.

\section{Results}

\section{Preliminary Analyses}

A manipulation check occurred following the completion of each condition; that is after each set of 12 kicks. This check was conducted to establish whether or not participants employed their assigned cue appropriately and supplemented the investigator's observation that all participants said their assigned phrases out loud prior to each kick. These self-report data confirmed observations. Another manipulation check item allowed the identification of any additional self-statements made prior to kicking in each condition; nearly all participants reported no additional self-talk. One participant did report saying an instructional cue "lift it" six times in a motivational self-talk condition and was subsequently removed. Two other participants reported using some additional self-talk which was consistent with the particular self-talk condition; as such their data were retained. 


\section{ACCEPTED MANUSCRIPT}

To test for the presence of an ordering effect, a presentation $4 \times 2 \times 2$ (order $\mathrm{x}$ foot $\mathrm{x}$ selftalk) mixed model ANOVA was conducted. Assumptions underpinning the analysis were not violated. Results from this analysis revealed the lack of main effect for presentation order as well as the lack of significant interactions involving ordering.

\section{Main Analyses}

Computation of a skill $\mathrm{x}$ self-talk $(2 \times 2)$ fully repeated ANOVA allowed for the examination of the study's hypotheses. Again, the assumptions underpinning the analysis were not violated. Results from the analysis confirmed the presence of a statistically significant main effect for foot in the direction one would expect, $F(1,39)=102.35, p<.001, d=1.32$. That is, participants executed the task more proficiently using their dominant foot $(M=19.33, S D=3.78)$ than on their non-dominant foot $(M=13.68, S D=4.76)$, with the difference between feet exceeding the recommended Cohen's $d$ threshold (Cohen, 1988) for a large effect (small > 0.2; moderate $>0.5$; large $>0.8$ ). However, a nonsignificant main effect for self-talk, $F(1,39)=0.1$, $p>.05, d=.03$, indicated no overall statistical difference between instructional self-talk $(M=$ $16.44, S D=4.86)$ and motivational self-talk $(M=16.57, S D=5.39)$. Importantly a significant omnibus interaction was noted between foot and self-talk, $F(1,39)=5.79, p<.05, \eta_{\mathrm{p}}{ }^{2}=0.13$, providing support to our hypothesis, signifying that the most effective type of self-talk for accuracy based tasks is dependent on the non/dominant foot of the athlete. To better understand the observed interaction post-hoc paired sample t-tests were conducted. These revealed support for the second hypothesis; skilled athletes using their dominant foot performed significantly better in the motivational self-talk ( $M=19.93, S D=3.53)$ as compared to the instructional selftalk $(M=18.75, S D=3.95)$ condition, $t(39)=-2.07, p<.05, d=.31$. However in the non- 


\section{ACCEPTED MANUSCRIPT}

dominant foot condition, despite the presence of a trend favoring instructional self-talk $(M=$ 14.13, $S D=4.76$ versus motivational self-talk $M=13.23, S D=4.83$ ) a nonsignificant difference emerged, $t(39)=1.39, p>.05, d=.20$.

\section{Discussion}

The present study examined the effectiveness of instructional and motivational self-talk for skilled performers when undertaking a task using their dominant and non-dominant limb. Partial support for the hypotheses was generated. Although skilled athletes completing the task with their dominant foot demonstrated significantly greater shooting accuracy when using motivational than instructional self-talk, no differences emerged when task execution involved the non-dominant foot.

With regard to dominant foot performance, the findings highlight the utility of drawing from theory outside of the largely atheoretically developed area of sports related self-talk. In this case use of Beilock et al.'s (2002) self focus conceptualization of attentional focus helped drive both the hypotheses and study design. In return the findings offer some empirical support for a strategy (i.e., motivational self-talk) that is ecologically valid and potentially helpful in preventing a self focus which has been shown to be detrimental for skilled performance. Nevertheless focus of attention was not assessed in the current investigation and there may be some alternative explanations for the dominant foot performance findings. Pilot testing ensured that the distance utilized in the current shooting task was close enough that all participants could comfortably kick the distance (even with their weaker foot); thus, down playing the role of strength in task execution. However, it is evident that this type of task is more ballistic than some other outcome based tasks present in the self-talk literature with a greater emphasis on fine motor 


\section{ACCEPTED MANUSCRIPT}

control (e.g., a short serve in badminton). As such successful execution of the shooting task used in the present investigation does not rely on strength but rather a relatively unique combination of precision and physical effort. Given that motivational self-talk is thought to impact on performance through psychophysiological activation pathways such as enhanced arousal levels, increased effort, and more positive mood state (Theodorakis et al, 2000), it is possible that motivational self-talk not only contributes via a more suitable (non-self) focus of attention, it might also help performers to adopt more appropriate activation states immediately before task initiation as compared to technique based instructional self-talk. Of course without additional measurements and a control group such explanations are difficult to gauge. However the present findings do illustrate why there is a clear need for more self-talk research to be conducted on (elite) athletes; findings gleaned from samples of novices do not necessarily apply to this more contextually relevant setting. Indeed Tod et al. (2011) reported that only approximately one fifth of all research examining the effect of self-talk on athletic performance had employed skilled participants. Of this the vast majority of the research has assessed whether or not self-talk brings about performance gains for skilled athletes. For example, Mallett and Hanrahan (1997) found that the use of strategic oriented instructional self-talk improved national level 100m sprint performance by a meaningful $2 \%$. The present study further develops our understanding of the use of self-talk by skilled athletes, offering some guidance for practitioners with regard to which type of self-talk is best to promote with their athletes, at least for tasks of the current nature. Examination of self-talk under competitive (e.g., Hatzigeorgiadis, Galanis, Zourbanous, \& Theodorakis, 2014) and/or stressful conditions would also likely extend this higher calibre athlete related evidence base and be welcomed by practitioners. The findings also dovetail with a 


\section{ACCEPTED MANUSCRIPT}

comment raised as part of the peer review process. More specifically, although there is empirical data to suggest that novice basketball players prefer motivational over instructional self-talk (Chroni, Perkos, \& Theodorakis, 2007), one reviewer stated that it was his/her experience from working with high level athletes that they too prefer motivational to instructional self-talk.

In contrast to dominant foot performance, no difference emerged between the two types of self-talk for non-dominant foot execution. It is possible that this finding supports the premise that the benefits of instructional self-talk are not as pronounced for non-dominant limb task execution compared to the much reported performance gains accrued by novices. In fact, while performance using instructional self-talk tended to be more accurate than motivational self-talk, there are a number of possible reasons why a significant difference was not found. On the one hand, from a statistical perspective, larger variances around the respective means would hamper the likelihood of obtaining a significant finding for non-dominant limb than dominant limb performance. On the other hand, from a self-talk perspective, athletes were not afforded the opportunity to familiarize and personalize their self-talk cues which might have reduced their effectiveness (cf. Hatzigeorgiadis et al., 2011). Furthermore, given the poorer performance (and thus greater room for learning) exhibited using the non-dominant as opposed to the dominant foot, future research investigating the effects of self-talk on non-dominant limb task execution might do well to utilize learning paradigms in their study designs. Indeed Zourbanous et al. (2013) reported much larger effect sizes when comparing non-dominant limb performance across a number of trials. From a longer term perspective research examining non-dominant skill acquisition has the potential to substantially aid coaches in their attempts of player development. 


\section{ACCEPTED MANUSCRIPT}

Although the present investigation is novel in that the effectiveness of motivational and instructional self-talk was examined using skilled performers, in order to place the findings in the context of the existent self-talk literature a few additional points need to be raised. For instance, since our study utilized a task specific to Gaelic football (albeit one which transfers to rugby and Australian rules football), more research is necessary in order to support or refute the generalizability of the findings. Accordingly different tasks incorporating a greater emphasis on fine motor control (e.g., golf putting) and/or more controlled or static actions (e.g., gymnastics moves such as arabesque) could be included within future study designs. While unnecessary for the current research question, future experiments would benefit from the inclusion of a control group. For example, the addition of skilled and unskilled control groups might enable further understanding about why the performance differences observed in the current investigate are present. This might be supplemented by the presence of baseline assessments, a greater number of trials, and a self-talk training phase (cf. Blanchfield, Hardy, de Morree, Staiano, \& Marcora, 2014).

Considered in concert, the findings lend some support to Zourbanous et al.'s (2013) revised matching hypothesis. In particular with regard to how skilled athletes might optimize accuracy oriented performance using self-talk. Continued examination of its predictions is warranted. From an applied perspective the findings challenge previous claims that greater use of self-talk is beneficial for athletes' success (Zervas, Stavroua, \& Psychountakia, 2007); rather they reinforce the importance of distinguishing between instructional and motivational self-talk. In addition the present findings illustrate to practitioners why consideration of the skill level of 


\section{ACCEPTED MANUSCRIPT}

their clients is important when constructing self-talk interventions and not to assume that findings from samples of novices unequivocally apply to skilled athletic competition. 


\section{ACCEPTED MANUSCRIPT}

\section{References}

Beilock, S. L., Carr, T. H., McMahon, C., \& Starkes, J. L (2002). When paying attention becomes counterproductive: Impact of divided versus skill focused attention on novice and experienced performance of sensorimotor skills. Journal of Experimental Psychology: Applied, 8, 6-16. DOI: 10.1037/1076-898X.8.1.6

Bell, J. J., \& Hardy, J. (2009). The effect of attentional focus on golf performance. Journal of Applied Sport Psychology, 21, 163-177. DOI: 10.1080/10413200902795323

Blanchfield, A., Hardy, J., de Morree, H. M., Staiano, W., \& Marcora, S. (in press). Talking yourself out of exhaustion: Effects of self-talk on perceived exertion and endurance performance. Medicine and Science in Sport and Exercise.

Chroni, S., Perkos, S., \& Theodorakis, Y. (2007). Function and preferences of motivational and instructional self-talk for adolescent basketball players. Athletic Insight, 9(1). Retrieved from http://www.athleticinsight.com/

Hanchar, H. J., Dodson, P. D., Olsen, R. W., Otis, T. S., \& Wallner, M. (2005). Alcohol induced motor impairment caused by increased extrasynaptic GABAA receptor activity. Nature Neuroscience, 8, 339-45. DOI: 10.1038/nn1398

Hardy, J. (2006). Speaking clearly: A critical review of the self-talk literature. Psychology of Sport and Exercise, 7, 81-97. DOI:10.1016/j.psychsport.2005.04.002

Hardy, J., Oliver, E., \& Tod, D. (2009). A framework for the study of self-talk in sport. In S. D. Mellalieu \& S. Hanton (eds.), Advances in Applied Sport Psychology. London: Routledge. 


\section{ACCEPTED MANUSCRIPT}

Hatzigeorgiadis, A., Galanis, E., Zourbanous, N., \& Theodorakis, Y. (2014). Self-talk and competitive sport performance. Journal of Applied Sport Psychology, 26, 82-95. DOI: $10.1080 / 10413200.2013 .790095$

Hatzigeorgiadis, A., Zourbanos, N., Galanis, E., \& Theordorakis, Y. (2011). Self-talk and sports performance: A meta-analysis. Perspectives on Psychological Science, 6, 348-356. DOI: $10.1177 / 1745691611413136$

Landin, D. (1994). The role of verbal cues in skill learning. Quest, 46, 299-313. DOI: $10.1080 / 00336297.1994 .10484128$

Schlaggar, B. L., Brown,T. T., Lugar,H. M. Visscher, K. M., Miezin,F. M., \& Petersen, S. E. (2002). Functional neuroanatomical differences between adults and school-age children in the processing of single words. Science, 296 (5572), 1476-1479. DOI:

$10.1126 /$ science. 1069464

Theodorakis, Y., Weinberg, R., Natsis, P., Douma, E., \& Kazakas, P. (2000). The effects of motivational versus instructional self-talk on improving motor performance. The Sport Psychologist, 14, 253-272.

Tod, D., Hardy, J., \& Oliver, E. (2011). Effects of Self-Talk: A Systematic Review. Journal of Sport \& Exercise Psychology, 33, 666-687.

Whiting, W. T. A. \& den Brinker, B. P. (1981). Image of the act. In J.P. Das, R. Mulcahy, \& A.E. Wall (Eds.), Learning difficulties (pp. 217-235). New York: Plenum.

Wulf, G. (2007). Attentional focus and motor learning: A review of 10 years or research. Bewegung und Training, 1, 1-11. 


\section{ACCEPTED MANUSCRIPT}

Zervas, Y., Stavroua, N.A., \& Psychountakia, M. (2007). Development and validation of the self-talk questionnaire (S-TQ) for sports. Journal of Applied Sport Psychology, 19, 142159. DOI: $10.1080 / 10413200601185156$

Zourbanos, N., Hatzigeorgiadis, A., Bardas, D., \& Theodorakis, Y. (2013). The effects of selftalk on dominant and nondominant arm performance on a handball task in primary physical education students. The Sport Psychologist, 27, 171-176. 